\title{
Contribution of Posterior Corneal Astigmatism to Total Corneal Astigmatism in a Sample of Egyptian Population
}

This article was published in the following Dove Press journal: Clinical Ophthalmology

\section{Mohamed Hosny (D) \\ Alaa Badawy \\ Lobna Khazbak \\ Mohamed Anis (D) \\ Sarah Azzam (ID \\ Ophthalmology, Cairo University, Giza, Egypt}

Correspondence: Mohamed Hosny

Ophthalmology, Cairo University, 84

Shehab Street, Mohandeseen, Giza I24II,

Egypt

Tel +20 1000007675

Email mohamedhosny@kasralainy.edu.eg
Purpose: To determine the percentage of contribution of the magnitude of posterior corneal astigmatism to total corneal astigmatism using Scheimpflug imaging.

Methods: This prospective cross-sectional study was conducted on 356 eyes of 356 patients, where the total corneal astigmatism was calculated by addition of anterior and posterior corneal astigmatism using vector analysis and then the percentage of posterior to total corneal astigmatism was calculated.

Results: The percentage of contribution of posterior to total corneal astigmatism was about $30 \%$ in patients with With The Rule astigmatism and about $8 \%$ in patients with Against The Rule astigmatism.

Conclusion: Posterior corneal astigmatism should not be neglected during calculation of total corneal astigmatism as neglecting posterior corneal astigmatism can result in errors during calculation and correction of astigmatism.

Keywords: posterior corneal astigmatism, total corneal astigmatism, Scheimpflug imaging, vector analysis

\section{Introduction}

Astigmatism is an error of refraction in which incident parallel rays cannot be focused to a single point. It could be corneal or lenticular astigmatism or both. Regarding Corneal astigmatism it is due to the difference in the corneal curvature in the different meridian of both the anterior and posterior surface. ${ }^{1}$ The anterior and posterior corneal surfaces contribute to total corneal astigmatism. Traditionally corneal power and astigmatism have been calculated based on anterior corneal measurements only, assuming a fixed posterior-anterior curvature ratio to estimate the contribution of posterior corneal power.

Newer technologies, such as slit-scanning technology, Scheimpflug devices, and optical coherence tomography are now used in the clinical setting for measuring the posterior corneal surface. ${ }^{2}$ However, it has been shown that relying only on the anterior corneal surface measurement and neglecting the relationship between the anterior and posterior corneal surfaces can lead to unacceptable intraocular lens (IOL) power calculation results after corneal refractive surgery and in errors during calculation of toric IOLs. ${ }^{3,4}$

The purpose of our study was to determine the percentage of contribution of the posterior corneal astigmatism to the total corneal astigmatism in a sample of Egyptian population using Scheimpflug technology. 


\section{Patients and Methods}

This prospective cross-sectional study was conducted on 356 eyes of 356 candidates presenting for refractive surgery in the interval between July 2019 and December 2019. The study was approved by both the Ethical Review Boards of Kasr Al Aini Medical School and Cairo University with an approval number of Ms184-2019 and followed the principals of the Declaration of Helsinki. The study was registered with ClinicalTrials.gov with a unique identifier: NCT04393740. The Cairo University Ethical Board prohibits the sharing of patient data in public depositories and any specific individual patient data can be obtained after a formal request to the Department of Ophthalmology Administrative office, Cairo University (ophthcairouni@gmail.com).

All patients were properly informed of the study and signed informed consent forms explaining the procedure and that their preoperative and postoperative scans will be used for scientific publication.

We included patients with corneal astigmatism $(0.5 \mathrm{D}$ up to $4 \mathrm{D}$ ), myopia up to $-8 \mathrm{D}$, Hyperopia up to $+4 \mathrm{D}$, patients with clear cornea and good quality Scheimpflug analyzer scans. We excluded patients with any history of cornel surgery or with co-existing corneal pathology. All candidates underwent Scheimpflug imaging using Pentacam (Oculus, Wetzlar, Germany). From the corneal parameters displayed on pentacam we calculated the: Anterior corneal astigmatism by subtracting ksteep- kflat on the front surface, posterior corneal astigmatism by subtracting ksteep- kflat on the Back surface. Total corneal astigmatism was calculated by addition of the anterior and posterior corneal astigmatism using Vector analysis using the "ASSORT vector calculator". Percentage of Contribution of the posterior corneal astigmatism to the magnitude of the total corneal astigmatism is then calculated. The ASSORT vector calculator is total planning and outcomes analysis software for astigmatism using Alpins method, cheltman, Victoria, Australia.

\section{Statistical Analysis}

Data were statistically described in terms of mean \pm standard deviation $(\mathrm{M} \pm \mathrm{SD})$. Data were tested for the normal assumption using Kolmogorov Smirnov test. Comparison between the study groups was done using Student $t$-test for independent samples in comparing normally distributed data and Mann Whitney $U$-test for independent samples for comparing not-normal data. Two-sided $P$-values less than 0.05 was considered statistically significant. All statistical calculations were done using computer program IBM SPSS (Statistical Package for the Social Science; IBM Corp, Armonk, NY, USA) release 22 for Microsoft Windows.

\section{Results}

Our study included 356 eyes of 356 candidates, age range of 18-45 years presenting for refractive surgery. All of them underwent Scheimpflug imaging using Pentacam (Oculus, Wetzlar, Germany). Patients were divided into two groups according to the type of astigmatism: Group 1: With the rule astigmatism (314 patients), Group 2: Against the rule astigmatism (42 patients).

In our study, mean anterior astigmatism in patients with Against the rule astigmatism was 1.205, and mean anterior astigmatism in patients with With the rule astigmatism was 1.825 and this was statistically significant $(P<0.001)$ (Figure 1).

The mean value of posterior astigmatism was 0.418 $( \pm 0.2296)$. In patients with With the rule astigmatism the value was $0.46( \pm 0.1931)$, and in patients with Against the rule astigmatism the value was $0.107( \pm 0.2433)$ and the results were statistically significant $(P<0.001)$ (Figure 2).

Contributions of anterior and posterior astigmatism in patients with With the rule astigmatism and in patients with Against the rule astigmatism are shown in Tables 1 and 2 respectively.

In our study, the mean contribution of posterior corneal astigmatism to total corneal astigmatism in all patients was $0.303( \pm 0.28)$ and in patients with Against the rule astigmatism it was $0.081( \pm 0.25)$, and in patients with With the rule astigmatism it was $0.331( \pm 0.28)$ with a $P<0.001$, which is statistically significant (Table 3 ) (Figure 3 ).

To sum up, the mean percentage of contribution of posterior astigmatism to total corneal astigmatism was about $30 \%$ in patients with With the rule astigmatism and $8 \%$ in patients with Against the rule astigmatism so the percentage of contribution of posterior corneal astigmatism to total corneal astigmatism is less in patients with Against the rule astigmatism.

\section{Discussion}

Corneal astigmatism is due to the difference in the corneal curvature in the different meridian of both the anterior and posterior surface. ${ }^{1}$ 


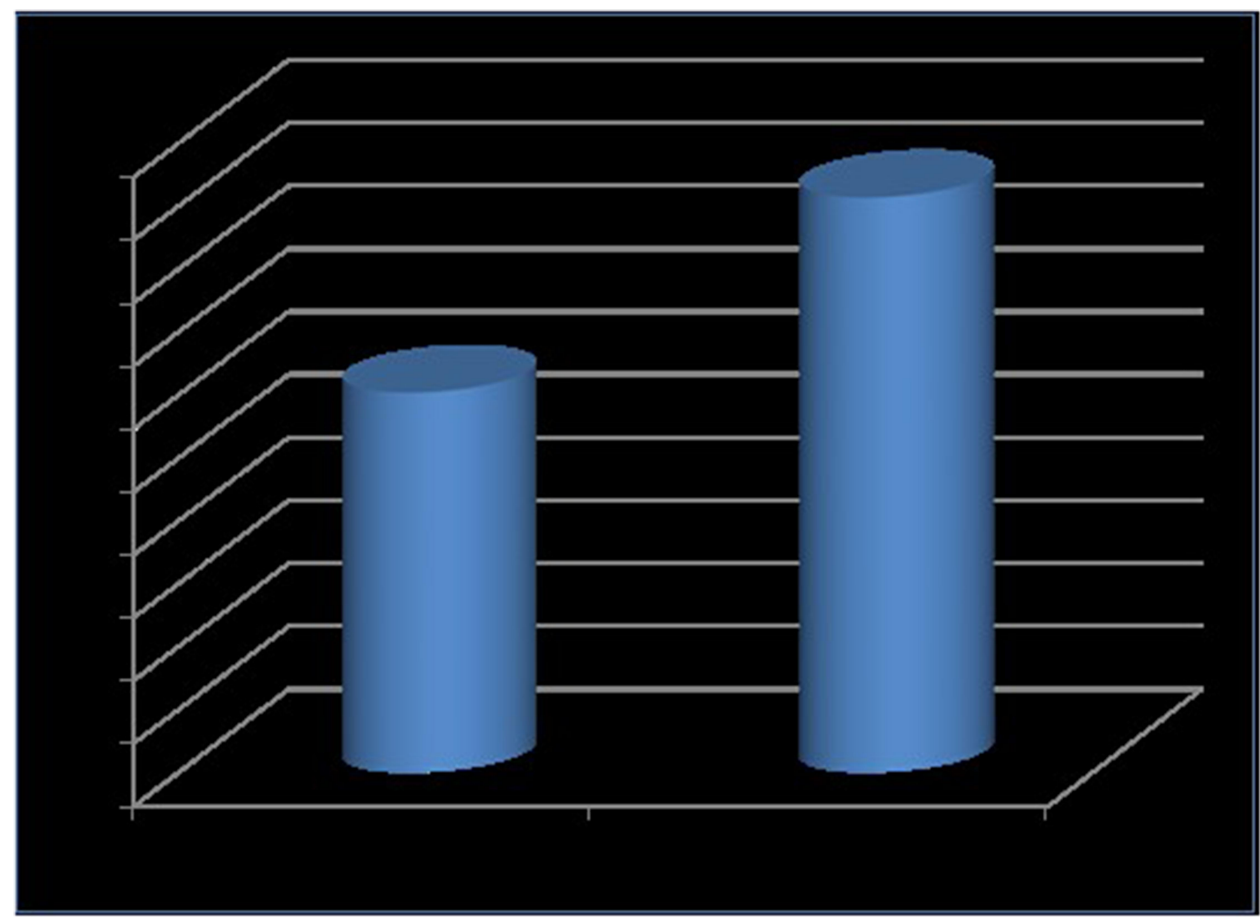

Figure I Percentage of the posterior corneal astigmatism to the total corneal astigmatism.

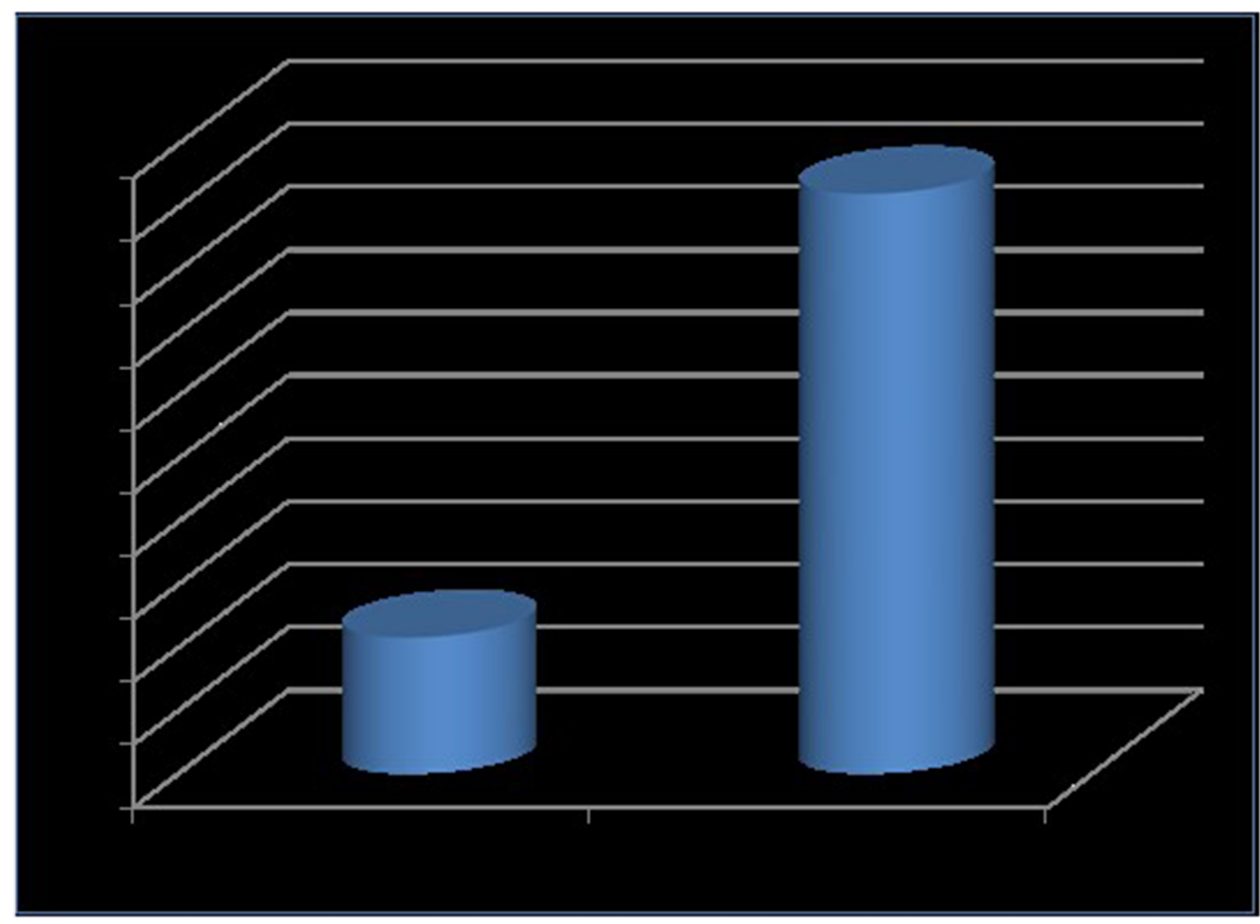

Figure 2 Mean posterior astigmatism in study groups.

Previously, the change in the posterior corneal surface was considered to play a more subtle role than the anterior corneal surface in optical performance because of the smaller difference in refractive indices between the cornea and aqueous, and it has been thought that the magnitude of PCA in the normal population is clinically negligible. ${ }^{5,6}$ But recent studies have found that the contribution of posterior corneal astigmatism is significant and cannot be neglected. 
Table I Contribution of Anterior and Posterior Astigmatism in Patients with the Rule Astigmatism

\begin{tabular}{|l|l|l|l|l|l|l|l|l|}
\hline \multicolumn{2}{|l|}{ Group } & $\begin{array}{l}\text { Ant } \\
\text { Astigmatism }\end{array}$ & $\begin{array}{l}\text { Ant. } \\
\text { Axis }\end{array}$ & $\begin{array}{l}\text { Post } \\
\text { Astigmatism }\end{array}$ & $\begin{array}{l}\text { Post. } \\
\text { Axis }\end{array}$ & $\begin{array}{l}\text { Total } \\
\text { Astigmatism }\end{array}$ & $\begin{array}{l}\text { Total. } \\
\text { Axis }\end{array}$ & $\begin{array}{l}\text { Post/ } \\
\text { Total }\end{array}$ \\
\hline $\begin{array}{l}\text { With the } \\
\text { rule }\end{array}$ & Mean & 1.825 & 86.74 & 0.460 & 94.14 & 1.390 & 85.00 & 0.331 \\
& $\mathrm{~N}$ & 314 & 314 & 314 & 314 & 314 & 314 & 314 \\
& SD & 0.8763 & 76.294 & 0.1931 & 77.081 & 1.1484 & 74.995 & 0.2815 \\
& Median & 1.700 & 83.60 & 0.400 & 100.10 & 1.380 & 80.00 & 0.290 \\
\hline
\end{tabular}

Table 2 Contribution of Anterior and Posterior Astigmatism in Patients with Against the Rule Astigmatism

\begin{tabular}{|l|l|l|l|l|l|l|l|l|}
\hline $\mathbf{n}$ & $\begin{array}{l}\text { Ant } \\
\text { Astigmatism }\end{array}$ & $\begin{array}{l}\text { Ant. } \\
\text { Axis }\end{array}$ & $\begin{array}{l}\text { Post } \\
\text { Astigmatism }\end{array}$ & $\begin{array}{l}\text { Post. } \\
\text { Axis }\end{array}$ & $\begin{array}{l}\text { Total. } \\
\text { Astigmatism }\end{array}$ & $\begin{array}{l}\text { Total } \\
\text { Axis }\end{array}$ & $\begin{array}{l}\text { Post/ } \\
\text { Total }\end{array}$ \\
\hline $\begin{array}{l}\text { Against the } \\
\text { rule }\end{array}$ & Mean & 1.205 & 3.08 & 0.107 & 177.43 & 1.320 & 3.00 & 0.081 \\
& $\mathrm{~N}$ & 42 & 42 & 42 & 42 & 42 & 42 & 42 \\
& $\mathrm{SD}$ & 0.6313 & 130.305 & 0.2433 & 149.989 & 0.7219 & 133.512 & 0.2526 \\
& Median & 1.100 & 4.45 & 0.200 & 169.85 & 1.280 & 2.00 & 0.156 \\
\hline
\end{tabular}

Table 3 Contribution of Posterior/Total Astigmatism in Study Groups

\begin{tabular}{|c|c|c|c|c|c|c|c|}
\hline \multirow[t]{2}{*}{ Item } & \multicolumn{3}{|c|}{ Against the Rule } & \multicolumn{3}{|c|}{ With the Rule } & \multirow[t]{2}{*}{ P-value } \\
\hline & Mean & SD & $\mathbf{n}$ & Mean & SD & $\mathbf{n}$ & \\
\hline $\begin{array}{l}\text { Post/ } \\
\text { total }\end{array}$ & 0.081 & 0.2526 & 42 & 0.331 & 0.2815 & 314 & $<0.001$ \\
\hline
\end{tabular}

In our study, we evaluated the contribution of posterior corneal astigmatism to total corneal astigmatism in 356 eyes using corneal tomography, Scheimpflug imaging using Pentacam (Oculus, Wetzlar, Germany). In our study, the mean magnitude of posterior corneal astigmatism was $0.418( \pm 0.23)$. In patients with With the rule astigmatism it was $0.46( \pm 0.19)$ and in patients with Against the rule astigmatism it was $0.107( \pm 0.24)$. The

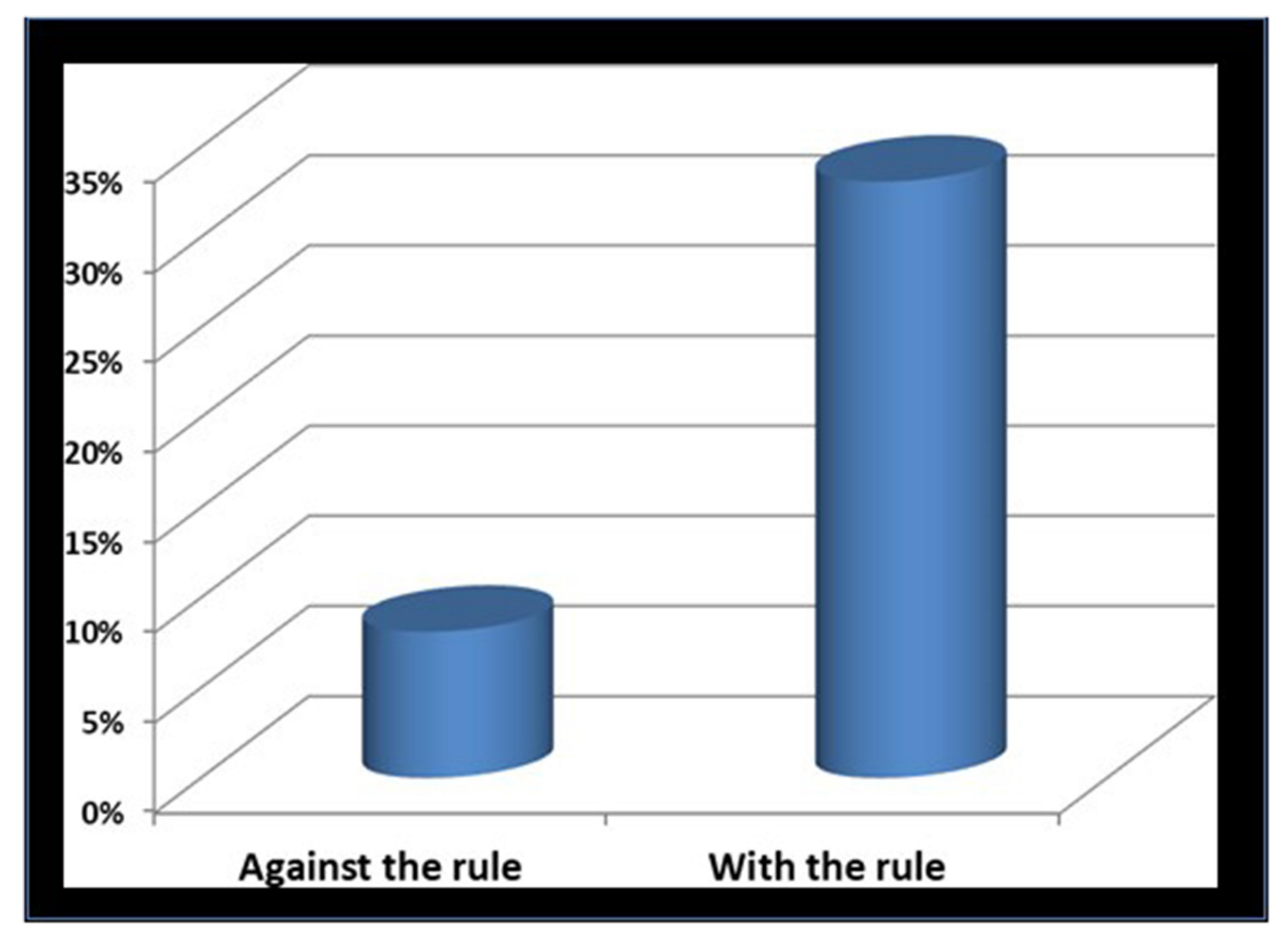

Figure 3 Percentage of the posterior corneal astigmatism to the total corneal astigmatism. 
percentage of contribution of the magnitude of posterior corneal astigmatism to total corneal astigmatism in our 356 patients was $30 \%$, in patients with With the rule astigmatism it was 33\%, and in patients with Against the rule astigmatism it was $8 \%$.

Our results are similar to the results of Koch et al, who evaluated the contribution of posterior corneal astigmatism to the magnitude of total corneal astigmatism using a Dual Scheimpflug analyzer (Galilei). The mean magnitude of posterior corneal astigmatism was $0.30( \pm 0.15 \mathrm{D})$. They also found that the anterior corneal measurements alone underestimate total corneal astigmatism by nearly $0.22 \mathrm{D}$ and this error exceeds $0.50 \mathrm{D}$ in $5 \%$ of eyes. They also concluded that the posterior corneal astigmatism tends to partially compensate for anterior corneal astigmatism in young adults with With the rule astigmatism and to increase total corneal astigmatism in older individuals. Because in most eyes posterior corneal astigmatism is aligned vertically, the error during toric IOL calculation would be overcorrection in eyes with WTR anterior corneal astigmatism and undercorrection in eyes with ATR astigmatism. $^{2}$

Also, our results were comparable to those obtained by Duane et al, who evaluated the posterior astigmatism toricity using Polaroid images, the posterior corneal surface radii were calculated along each meridian assuming a value of 1.3771 for the corneal refractive index. It was conducted on 80 eyes, the mean magnitude of posterior corneal astigmatism was $0.38 \pm 0.03$. They found that the posterior corneal surface of both gender groups exhibits more toricity than the anterior corneal surface so it was concluded that the simple addition of a posterior corneal surface of equal toricity to the anterior cornea had the dioptric effect of reducing the total corneal astigmatism by approximately $5 \%{ }^{7}$

Similarly, were the results of Dubbleman et al, who conducted a study to determine the shape and astigmatism of the posterior corneal surface in a healthy population, using Scheimpflug Photography (Topcon SL-45 camera). The mean magnitude of posterior corneal astigmatism was an average of $0.32 \pm 0.01$, and the astigmatism of the posterior corneal surface $(0.305 \mathrm{D})$ compensates the astigmatism of the anterior corneal surface (0.99D) with $31 \%{ }^{8}$

Our results were also similar to the results of Ho et al. The corneal astigmatisms of 493 subjects were measured using a rotating Scheimpflug camera (Pentacam; Oculus, Wetzlar, Germany). The keratometric corneal astigmatism (KA) was obtained by using the anterior corneal surface measurement and the keratometric index (1.3375) while neglecting the posterior corneal surface measurement. The mean arithmetic and absolute estimation errors of the total corneal astigmatism using keratometric index and constant anteroposterior ratio without the need for measurement of the posterior corneal surface was $0.06 \pm 0.28$ diopter, which means that it provides a good estimation of the posterior corneal power. They concluded that neglecting the posterior corneal surface measurement may lead to significant deviation in the corneal astigmatism. ${ }^{9}$

On the other hand, our results were different than the results of Prisant et al, who conducted a study to detect whether vector summation of anterior and posterior topographical astigmatism improves the prediction of refractive astigmatism better than anterior topographical astigmatism alone. The mean posterior astigmatism was $0.66( \pm 0.23)$, which is more than our results. ${ }^{10}$

Our results were also different from those of Modis et al, who conducted a study on 88 healthy corneas of 44 normal subjects, the mean magnitude of posterior corneal astigmatism was $0.78( \pm 0.61)$. This difference can be attributed to their smaller sample size and using a different device to assess the posterior corneal astigmatism (scanning slit topography). ${ }^{11}$

To our knowledge no other studies have assessed the contribution of posterior corneal astigmatism as a percentage of total corneal astigmatism in an Egyptian population.

In conclusion studying the posterior corneal astigmatism is of utmost importance in the measurement of the toric IOLs which are used to correct astigmatism. Accurate calculation of the toric IOL power requires accurate measurement of the total astigmatism, including both the anterior and posterior corneal astigmatism, as neglecting the posterior corneal astigmatism can lead to undercorrection of Against the rule astigmatism and overcorrection of With the rule astigmatism.

\section{Acknowledgments}

This manuscript has been read and approved by all the authors, and the requirements for authorship have been met, and each author believes that the manuscript represents honest work.

\section{Disclosure}

None of the authors have any financial interest in any product or material used in this study. No competing financial interests exist. The authors report no conflicts of interest for this work. 


\section{References}

1. Harris WF. Astigmatism. Ophthalmic Physiol Opt. 2000;20(1):11-30. doi:10.1046/j.1475-1313.2000.00484.x

2. Koch DD, Ali SF, Weikert MP, Shirayama M, Jenkins R, Wang L. Contribution of posterior corneal astigmatism to total corneal astigmatism. J Cataract Refract Surg. 2012;38(12):2080-2087. doi:10. 1016/j.jcrs.2012.08.036

3. Gimbel HV, Sun R. Accuracy and predictability of intraocular lens power calculation after laser in situ keratomileusis. $J$ Cataract Refract Surg. 2001;27(4):571-576. doi:10.1016/S0886-3350(00)00795-1

4. Randleman JB, Loupe DN, Song CD, et al. Intraocular lens power calculations after laser in situ keratomileusis. Cornea. 2002;21:751-755. doi:10.1097/00003226-200211000-00003

5. Rydström E, Westin O, Koskela T, Behndig A. Posterior corneal astigmatism in refractive lens exchange surgery. Acta Ophthalmol. 2016;94(3):295-300. doi:10.1111/aos.12965

6. Koch DD, Jenkins RB, Weikert MP, Yeu E, Wang L. Correcting astigmatism with toric intraocular lenses: effect of posterior corneal astigmatism. J Cataract Refract Surg. 2013;39(12):1803-1809. doi:10.1016/j.jcrs.2013.06.027
7. Dunne MC, Royston JM, Barnes DA. Posterior corneal surface toricity and total corneal astigmatism. Optom Vis Sci. 1991;68 (9):708-710. doi:10.1097/00006324-199109000-00006

8. Dubbelman M, Sicam VA, Van der Heijde GL. The shape of the anterior and posterior surface of the aging human cornea. Vision Res. 2006;46:993-1001. 6-7. doi:10.1016/j.visres.2005.09.021

9. Ho JD, Tsai CY, Tsai RJ, Kuo LL, Tsai IL, Liou SW. Validity of the keratometric index: evaluation by the pentacam rotating scheimpflug camera. J Cataract Refract Surg. 2008;34(1):137-145. doi:10.1016/j. jcrs.2007.09.033

10. Prisant O, Hoang-Xuan T, Proano C, Hernandez E, Awad S, Azar DT. Vector summation of anterior and posterior corneal topographical astigmatism. J Cataract Refract Surg. 2002;28(9):1636-1643. doi:10.1016/S0886-3350(01)01258-5

11. Módis JL, Langenbucher A, Seitz B. Evaluation of normal corneas using the scanning-slit topography/pachymetry system. Cornea. 2004;23(7):689-694. doi:10.1097/01.ico.0000126315.05519.0b
Clinical Ophthalmology

\section{Publish your work in this journal}

Clinical Ophthalmology is an international, peer-reviewed journal covering all subspecialties within ophthalmology. Key topics include: Optometry; Visual science; Pharmacology and drug therapy in eye diseases; Basic Sciences; Primary and Secondary eye care; Patient Safety and Quality of Care Improvements. This journal is indexed on PubMed

\section{Dovepress}

Central and CAS, and is the official journal of The Society of Clinical Ophthalmology (SCO). The manuscript management system is completely online and includes a very quick and fair peer-review system, which is all easy to use. Visit http://www.dovepress.com/ testimonials.php to read real quotes from published authors. 